ISSN: 2162-3104 Print/ ISSN: 2166-3750 Online

Volume 8, Issue 4 (2018), pp. 1483-1498

(C) Journal of International Students

http://jistudents.org/

doi: $10.5281 /$ zenodo. 1468088

\title{
International Graduate Student Labor as Mergers and Acquisitions
}

\author{
Brendan Cantwell \\ Michigan State University, USA \\ Jenny J. Lee \\ University of Arizona, USA \\ Yeukai Mlambo \\ Arizona State University, USA
}

\begin{abstract}
This study critically examines the self-reported experiences of international graduate students using a framework understanding internationalization as acquisitions and mergers. Students reported positive experiences with their advisors. However, students' accounts of laboratories and other research settings were diverse, ranging from co-contributors to knowledge and respected collaborators to employed cheap labor that their advisors depended upon for their own gains. In some cases, these students feared that their funding would be cut off or dismissed from the program (and consequently deported from the US) if they challenged their advisors. Whether such apprehensions were valid is unknown as this study focused on perceptions of the students only. The findings do lead to important future directions for research and practice.
\end{abstract}

Keywords: academic mobility, acquisitions, graduate education, internationalization, international students, higher education, mergers

Increased scientific production worldwide, coupled with growing policy emphasis on economic growth through scientific innovation and status competition vis- à -vis global university rankings, means that universities in different countries compete in order to advance their research standing (Cantwell \& Taylor, 2013; Pusser \& Marginson, 2014). In the United States (US), one strategy to compete in the global research arena has been to attract international graduate students (Taylor \& Cantwell, 2015). Each year, US higher education institutions expend over $\$ 60$ billion on science and engineering (S\&E) research and publish over 200,000 scientific articles, accounting for approximately $25 \%$ of global article output (National Science Board [NSB], 2014). While metrics about academic research are aggregated at the national level, individuals originating from outside of the US make indispensable contributions. As one indicator, about one-third of all papers attributed to the US are coauthored with a collaborator located aboard (NSB, 2014). 
Multinational collaboration with US universities occurs as well, comprising international research teams within US institutions. Above all else, graduate education may be the most direct way in which US academic research is supported internationally (Taylor \& Cantwell, 2015). US universities, in fact, rely heavily on graduate students from abroad (Stephan 2012). Approximately $30 \%$ of graduate students enrolled in S\&E programs in the US are temporary residents (NSB, 2014). In some fields, such as physics and engineering, the number of international doctoral students outnumbers US students (NSB, 2014). Evidence further suggests that international graduate students make outsized contributions to research. Foreignborn researchers tend to be more research active and productive than their US-born counterparts (e.g. Cantwell \& Lee, 2010; Corley \& Sabharwal, 2007; Stephan, 2012; Webber, 2012).

Many internationally mobile graduate students choose to study in the US, at least in part, because of the size, status, and high resource level of the US higher education system (Lee, 2007). US colleges and universities also seek to attract international graduate students in order to capture their research contributions (Cantwell \& Lee, 2010; Cantwell \& Taylor, 2013; Stephan, 2012; Taylor \& Cantwell, 2015). In other words, internationalization can be understood as a component of institutional competition strategies.

Foci on "motivations" and "rationales" (e.g. Altbach \& Knight, 2007) have long implicitly presented internationalization as strategic processes. By developing a framework for understanding internationalization "mergers and acquisitions," Deschamps and Lee (2015) explicitly conceptualize internationalization strategy as advancing the interests of higher education intuitions (HEIs). Through acquisitions, HEIs acquire resources internationally (often in zero sum competition), whereas mergers occur when intuitions participate in mutually beneficial cross-border partnerships. While the mergers and acquisitions framework proved useful for understanding how senior international affairs administrators understand internationalization (Deschamps \& Lee, 2015), it has not been used to examine other dimensions of internationalization. The purpose of this study is to understand how international students in science and engineering fields perceive their experiences in light of the mergers and acquisitions framework.

Giving attention to science and engineering students is appropriate for several reasons. First, inward student mobility is one of the primary mechanisms by which higher education institutions (HEIs) internationalize. Second, specific focus on science and engineering is appropriate because (a) the academic research enterprise in that field is highly internationalized, (b) scientific research is one area in which HEIs compete directly with one another across borders, and (c) graduate students are significant contributors to research. Third, international graduate students are well placed to understand the way internalization works "on the ground" because they are at the front lines of the process. International students possess agency and are capable of self-authoring identities in relation to their transnational experiences (Marginson, 2014) and early-career scientists use mobility experiences to negotiate the best available opportunities for themselves (Cantwell, 2011). Hence, we assume this group of students to be self-possessed and capable of presiding the realities of their places within the internationalizing academy.

\section{LITERATURE REVIEW}

Each year approximately 600,000 students enroll in S\&E graduate programs and approximately 200,000 of those are temporary residents in the US (NSB, 2014). The science policy literature 
has focused on the importance of these international students to the US research enterprise. For example, research has found international graduate students appear to produce more research papers than do their domestic counterparts (Corley \& Sabharwal, 2007), suggesting these students make valuable contributions to academic R\&D (Black \& Stephan, 2010). Stephan (2012) argued that faculty members prefer to support students whom they believe will be more productive. According to Cantwell and Lee (2010), faculty members often seek out international students and postdocs because their increased productivity, in terms of publishable research outputs, is helpful in securing future research funding.

Despite the reputation of international graduate students as productive researchers, they nonetheless face significant challenges in adjusting to a new academic environment. For instance, a number of studies have examined challenges related to the social, psychological, and cultural adjustment that takes place when living and studying in a foreign country (e.g. Chapdelaine \& Alexitch, 2004; Poyrazli, et al., 2002; Zhou \& Todman, 2009). Such studies have given attention to factors such as the extent to which international and domestic graduate students interact socially (Trice, 2004), the ways in which classroom environments might inhibit international graduate students' learning and sense of belonging (Kim, 2011), the effects of language challenges on international graduate students' experiences (Cheng \& Erben, 2012; Kuo, 2011), and sources of potential conflict between these students and their advisors (AdrianTaylor, et al., 2007).

The tensions in student-advisor relationships, in particular, have been found to influence international graduate students' development as future researchers. While international graduate students' experiences with their advisors have received limited attention, several studies have addressed the issue of relational conflict. A study by Adrian-Taylor, Noels, and Tischler (2007) examined conflict between international graduate students and their advisors at a Canadian University. Adrian-Taylor and colleagues (2007) found that approximately $34 \%$ of advisors and $22 \%$ of students reported conflict, with both groups reporting "different expectations regarding responsibilities" as a leading cause of strain in the advisor - student relationship (p. 101). This finding is provocative because it suggests there may be the some potentially inherent conflict, or at least misunderstanding, associated with the expectations of international students, who might view their education as a path towards their future personal goals, and advisors, who might see international graduate students as central to advancing their own research agendas. Other research indirectly supports the proposition that international graduate students in S\&E fields may experience conflicts in their research roles. For example, studies on the experiences of international postdoctoral researchers, commonly known as postdocs (Cantwell \& Lee, 2010), and international graduate students (Lee \& Cantwell, 2012) found that these individuals frequently experienced what they perceived to be exploitation by advisors who saw them as good workers but not as trainees with the potential to become independent scientists.

In general, the literature has both documented international students' research productivity and analyzed their transition experiences. Yet the literature has not considered international students within the context of the way they perceive the research and internationalization strategies of the universities in which they study. As outlined above, international students' perceptions about how their experiences relate to HEIs' internationalization and competition is significant because they are at the front line of internationalization and key inputs that fuel institutions' research enterprise. Furthermore, US dependency on international scientists, including graduate students, to maintain its position as the world's leading producer of scientific research (Cantwell \& Lee, 2010) makes this study especially important. 


\section{CONCEPTUAL FRAMEWORK}

Internationalization had long been seen as a process reflecting the ways in which higher education organizations are responding to or participating in globalization processes (Altbach \& Knight, 2007; Knight, 2003; Marginson \& van der Wende, 2007; De Wit, 2009). When such responses are shaped by organizational goals, they can be understood as strategy. Internationalization strategy has generally been seen as the responsibility of institutional leaders and specialized professionals who are dedicated to managing the university's international activities (Deschamps \& Lee, 2015). A limitation of viewing internationalization as a strategy in response to globalization is the tendency to assume HEIs are able to engage in internationalization strategy rationally, coherently, and with full autonomy (Cantwell \& Maldonado-Maldonado, 2009).

Yet as Altbach and Knight (2007) point out, "internationalization is a two-way street" because people, information, and resources flow in multiple directions, even though wellestablished institutions in the Global North have the most power in internationalization processes (p. 291). While there is no question that initiations from the Global North occupy the most advantageous and powerful positions, no single institution is fully in control of its own destiny (Marginson, 2007). Hence, it may be more useful to understand internationalization strategy as part of "comprehensive internationalization" which involves examining the role of faculty and students and not just campus administrators (Hudzik, 2014).

This study sought to understand how international students in science and engineering fields perceive their academic experiences. Their accounts were examined in light of the mergers and acquisitions framework used by Deschamps and Lee (2015). Understanding internationalization through a mergers and acquisitions framework views research universities competing on a global basis for status and resources. The US has long been the leading player in academic science, but data collected by the National Research Council (2012) show massive growth in the number of "indexed" S\&E papers produced in countries such as China, Brazil, and Turkey. These data show that while the US may not be falling behind, other countries are catching up in terms of academic R\&D prowess. Increased scientific production worldwide, coupled with the rise of global university rankings means that universities in different countries increasingly compete with each another in order to advance their research standing (Cantwell \& Taylor, 2013; Pusser \& Marginson, 2014). In the US, one strategy to compete in the global research arena has been to attract international graduate students (Cantwell \& Taylor, 2015). In this way, internationalization of the study body and research teams can be understood as a means of acquiring resources.

Indeed, Deschamps and Lee's (2015) study of university international offices found that international efforts often involve improving institutional standing by gaining additional resources internationally. Borrowing language from the corporate strategy literature, Deschamps and Lee found that internalization is achieved through merger and acquisition mechanisms. Mergers are internationalization partnerships with mutual benefit. According to the authors, "[m]ergers refer to programs that simultaneously benefit either partnering institutions or countries[,]"(Deschamps \& Lee, 2015, p. 131), while acquisitions may not be mutually beneficial but instead only benefit the host intuition. "In the context of international education, acquisitions can be understood as activities focused on the acquiring of resources from abroad," (Deschamps \& Lee, 2015, p. 131). In this study, we extend the idea of mergers and acquisitions to examine the extent to which international students' experiences are related to mergers and/or acquisitions within the context of internationalization as a research 
enterprise. Attention to students' lived experiences is consistent with a comprehensive approach to understanding internationalization.

We examined how international graduate students in S\&E fields described their role, their relationship with their advisor, and the differences between students' goals and what they perceived as their advisors' goals. In doing so, we sought to discover if internationalization of the research enterprise involved the concept of mergers, acquisitions, or both. In this case, we examined the extent to which students reported evidence of mutually beneficial experiences (mergers) or being treated as research commodities (acquisitions).

\section{RESEARCH METHOD}

This qualitative study explored how international graduate students in S\&E fields perceived their experiences in light of the mergers and acquisitions internationalization framework. This study analyzed interview data in what Merriam (2009) calls "basic" qualitative analysis. Basic qualitative research involves using qualitative data to interoperate and make sense of social phenomena. In total, 44 students were interviewed at two research universities in the United States herein referred to by their pseudonyms as Mid-West University (MWU) and South-West University (SWU). Both are large public research universities, ranked in the top 200 by the Times Higher Education's World University Rankings, and both are members of the prestigious Association of American Research Universities (AAU). All interviewees were enrolled in a science or engineering graduate program. Twenty-one students were interviewed at MWU and 23 were interviewed at SWU. Participants comprised of 21 females and 19 males. Among the participants, 33 were enrolled in doctoral programs, and 11 were enrolled in masters programs. Participants had spent between 1 and 6 years at their respective institutions. Students represented the continents of Asia, Europe, North and South America. Students from Africa and Oceania were not represented in the sample due to a) their relatively low enrollment rates compared to other regions in the institutions and b) a reliance on snow-ball sampling. All interviews were guided by a semi-structured interview protocol and lasted approximately one hour. Interview questions addressed why students chose to study in the US, interactions with their advisors and peers, research and educational activities, and their goals for the future.

Participants were recruited in varied ways such as open invitations, direct invitations, and referrals. Approximately half were volunteers who responded to an open invitation sent via an international student listserv. Another quarter were identified through departmental websites as most science and engineering departments at US universities keep up-do-date websites with information about faculty and graduate students. The remaining quarter were identified through snowball sampling. Interviews were transcribed soon after being conducted and notes were taken after initial review of interview data. Participant recruitment continued until saturation was achieved at both sites. Data saturation occurs when additional interviews add little or no new information. Interviews were coded by sequentially by institution, following an open coding process. Open coding involves inductively segmenting interview data into thematic categories or codes, which become the building blocks for analysis (Corbin \& Strauss, 1990). Codes across intuitions were compared through thematic analysis in light of the mergers and acquisition framework. Each of the authors were involved in coding transcripts as a method to improve the reliably of analysis. 


\section{FINDINGS}

In addition to running their own research projects, most graduate students worked as research and teaching assistants, assisted with grant writing, and supervised training of undergraduate students in laboratories. These different roles contribute to the overall research endeavors taking place in higher education institutions. Variation in international STEM student experiences was not patterned by institution or major but was rather directly related to their relationship to their advisor (the terms, "advisor," "supervisor," and "primary investigator" (PI) are used interchangeably). In most cases, the advisor was not only the students' academic supervisor but also the person for whom they worked as either a teaching or research assistant. Student-advisor relations proved to be the most important factor in shaping international students' experiences. This finding is consistent with research showing the lab is the primary unit of organization in academic science (Owen-Smith, 2002; Stephan, 2012; Cantwell, 2015). Students described a range of experiences. Some felt their relationships with their advisor were mutually beneficial and collegial in nature, and can be understood using the concept of mergers. Others described experiencing exploitative labor conditions and felt as if they were serving their advisor's interests over their own, which can be understood using the concept of acquisitions. These experiences provide useful insights into internationalization of the academic research enterprise.

\section{Mergers}

Many students' accounts can be understood as examples of international mergers. These students explained how their study was mutually beneficial to both themselves and to their advisor. Sub-themes that emerged included (a) students as co-contributors of knowledge with their advisor, and (b) co-contributors of knowledge as part of a research team, and (c) students as respected collaborators.

\section{Knowledge Co-Contributors with Advisor}

Contribution to knowledge creation, alongside their advisor and/or research team, is one sub-theme among students in the mergers category. While nearly all students interviewed discussed research training as the main purpose of their education, 10 , or about $25 \%$ of the students interviewed clearly articulated how they were co-contributing to their respective field of science. Accounts of education and work from this group of emphasized student agency in establishing relationships with advisors that were mutually beneficial. As researchers, these students helped shaped the direction of their respective research projects, with the advisor serving as a consultant. These students perceived themselves as co-contributors to knowledge and described persuading prospective advisors that they could each benefit from the relationship in different ways.

Fung (pseudonyms were used for all participants), for example, described how she proactively switched advisors in order to establish a working relationship that allowed her to make co-equal contributions to research:

I talk[ed] to different people including the professors to try [to find a good fit]. I directly went to talk to my current advisor so to just recommended myself. I say that because I'm interested. You know, "So, could you let me just first maybe just observe, as an observer to see, so what, what, what people in your lab is doing?" ...I did some work for her and so I helped her some and then so I help for some 
time and so, both my current advisor and [I]... felt ... we are a good fit to each other. (Fung, F, Asia)

For some students, these collaborations resulted in students helping to shape the direction of their advisors' research program. When asked about the extent of her input, Jan responded:

I would say it was 50/50. I was given a grant and, and we didn't, it said this is the part that's sort of knowledge gap that we need to pursue and I started off with that project and sort of went off in my own way and then discovered something and then sort of changed the research direction. So I would say 50/50. (Jan, F, Asia)

In other cases, students played a more influential role in contributing to the direction of their lab research:

So it was kind of hard in the beginning, but then I started getting some good results out of that and one of the results kind of changed everything that we were doing in the lab. So we were more focusing on studying one plant hormone and now we're focusing on a totally stuff because of the results that we got and, and I consider that's even affecting the other lab members because they're also having to change their approach to that different condition that we found now because my boss is now trying to apply for a grants on that part. (Abrahan, M, South America)

Examples such as those presented by Fung, Jan, and Abrahan illustrate how international STEM graduate students enter into relationships with their respective advisors that can be understood as examples of internationalization through mergers. Students bring energy, knowledge and skills to host institutions that have resources necessary to conduct research (e.g. labs, equipment), existing programs of research, and experience guidance from faculty members. In such cases both parties can benefit.

\section{Knowledge Co-Contributors as Part of a Research Team}

In several cases, students described their most mutually beneficial experiences as being an essential part of a larger research team. Collaboration within the laboratory space was encouraged by advisors.

My instructor always says it's your project not mine but actually he got the funding for that project. So I think it's like the project for the group and then he assigns the sub-project to you so you are taking responsibility for completing this project. Then, in that case, you have not completed project alone so you have to ask for help, like you have to collaborate with other researchers in other labs or the researchers in the same group. (Chao, M, Asia)

There was also evidence of the student peer environment serving as an important collaborative venue. As one student shared, "I think I'm happy now and in this group, because I can learn a lot more techniques than mass spec... You can't think sometimes by yourself. ... So I learn a lot more in this group" (Bai, F, Asia). In addition, Liu highlighted the benefits of peer collaboration with researchers from other cultures:

I feel like it's like more, you have more opportunity interacting with people all around the world in the science community regarding to your research. Another reason actually why I feel like I'm really being international is that it's actually after I came here I kind of finally realized the difference you know Chinese culture, 
American culture. Like, European culture. They're all different... I feel like if I stay in China I might not have a lot of opportunity collaborating with people around the world. (Liu, F, Asia)

The synergy between student and advisor was often attributed to how graduate students felt that they could complement the expertise of their advisors, as illustrated by the following extracts:

So I'm working on trying to measure a compound in plants that is very, very low [in] abundance and my PI doesn't really work on this type of machine and so I have to go back and forth to the facility with the people that actually knows the machine and my PI who actually knows the biology of things. So I have to connect the dots, in a sense, because sometimes I feel like I don't have a set of protocol, established protocol, so I have to make it up as I go, which may or may not be correct. (C.J., M, Asia)

I finished the first part of the project I become the person who know [s] the project best, even better than my advisor because I'm focusing on the, my project. During that time, I was able to propose some future directions so and whether to scale up or further improvement. So, I think this is one influence, impact that I have for the lab. (Saad, M, Middle East)

There was also some indication that the collaboration would continue well past a student's time at the university:

I think I can improve the research by doing whatever we can do in Indonesia because the problem is there and I can get as many samples as I want and then just do and continue the collaboration. So I can do whatever I can do from Indonesia and then the rest, I can do collaboration. (Matius, M, Asia)

\section{Respected Collaborators}

Most students described advisors as being supportive of their aspirations. Approximately half of the students interviewed articulated specific ways in which advisors supported their educational and post-educational goals including finding employment in the US or in the students' respective home countries. This support can be understood as a form of internationalization though mergers because advisors appeared to be especially supportive when the advisor and student's agendas aligned. Take for instance Daan's experience:

One thing I really appreciate about him [my advisor] is he really try to help student develop [the] CV to carry on after the degree here. He really care [s]. Like if he know [s] you are not enough he will find you some opportunity. Like maybe he [says], "Maybe you can write this review or maybe you should go with me to meet some people...My job is to make sure you graduate on time.” (Daan, M, Asia)

Daan's experience may demonstrate student-centered support from his advisor. But faculty members are also partly evaluated by the number of their students who achieve timely graduation. Other students including Sara (Asia), Faisal (Asia), and Abrahan (South America) variously described advisor support though providing opportunities to acquire teaching experience by guest-lecturing in their classes, advice on how to present research findings at conferences and in articles, and providing flexible work schedules that accommodated students' 
personal responsibilities. While each case provides an example of student support, the support may also yield benefits for the advisor, including assistance with teaching, better and more conference presentations and publications, and a flexible working environment that promotes more results in the long run.

Like Abrahan, Hooman's advisor was flexible about working hours. According to Hooman (a male student from the Middle East), a flexible approach is good for the student but can also benefit advisors' research over time: "[My advisor] understands the fact that this is research. If you want research to go on for a long period of time, you need to be flexible with people. Who cares where you are working as long as you are doing your work?" Hooman's account shows how student support can be mutually beneficial. When Hooman's advisor ran out of grant funding he had an opportunity to move to a different lab and work with a faculty member who had more resources. However, Hooman chose not to switch advisors because, in his own words, "I love my project! I really enjoy working with my supervisor." In other words, supporting students can pay dividends through loyalty and commitment.

While these instances depicted a rather ideal relationship between graduate student and advisor, only one quarter of participates clearly described how they made independent contributions that led to mutual gain. A larger portion of the sample described collaborating with their advisor, but most did not clearly identify shared benefits from the exchange. Further, most of these cases were dependent upon the students' initiative and efforts that may be beyond what is typically expected for students to make. For example, Xenon from Asia explained that while his contribution to research was mutually benefit, securing influence over the research process took two years and required that he become a de facto lab manager who supervised other students' work and was responsible for ordering equipment and supplies.

\section{Acquisitions}

While several of interviewees indicated a merging of talents and resources, a majority of students also discussed their experiences within the concept of the acquisitions. Included in the idea of acquisitions were (a) students as the employee, (b) students as cheap labor, and (c) students being financially and legally dependent on their advisor.

\section{Employee}

In describing their relationships with advisors, students shared that their advisors were their employer and the students were employees. Many students explicitly used the term "boss" to refer to their advisor. For example, Sara said, "I mean, he usually not teach us a lot. So it's more like work for boss. You need to solve problem by yourself" (Sara, F, Asia). This type of relationship included students working alone, limited direct advisor training and some student autonomy over individual research projects while still being accountable to their advisor.

My boss is will not tell you directly what needs to be done, what kind of experiments you need to do. He likes to guide in your mind and he lets you come up with what you need to do next. (Fung, M, Asia)

While students had some autonomy in their work, in this boss-employee relationship, some students did not feel they were learning anything. Eshan shared:

He just wants me to work. How can I describe that? He just tells me, "Ok I want this result. I want to try this method and I want the results." And that's basically my job to do that. I mean I don't learn anything after some time. I mean he thinks 
that you are not learning any technical details and he thinks that is fine because through that, through this work I'm learning scientific reasoning and those kind of things. (Eshan, M, Asia)

Consistent with an employer-employee relationship, there was a sense of the supervisors' ownership over the students and their time:

Once I got there 9:15, like so 15 minutes over according to the 9 to 5 or 9 to 6 expectation and he sent me an email, "if you are late, you have to send me an email and let me know," and that was the beginning of me thinking like, that's weird. I had friends who were going to the lab like at 10, 11, and their PIs are ok ... they also leave at 10, 11. I will work as much as my work wants me to work, but I'm a human. Sometimes I need an hour of sleep because I slept like, at 4 last night working. I wasn't doing anything else because I really don't, we don't have much of a life (laughs). (Hooman, Middle East, M)

He's always trying to see what everybody's doing. So he's always concerned if somebody from his lab is not in the lab physically, he's trying to call the person, 'Why you're not in the lab? Why you don't come back? I want [you] to be here in the lab from 8 am to 7pm, 'so he's not a very nice guy." (Abrahan, South America)

\section{Cheap Labor}

While almost all of the interviewees described their hard work ethic, some felt they were taken advantaged of as cheap labor. In differentiating international from local graduate students, an interviewee stated, "I think international students put on more hours of work. They're kind of more worried, they feel they have to do more. You will see them working for longer and longer and longer hours." (Suzy, F Caribbean) In describing what she thought was a bad advisor, Lui said,

[Some advisors] don't really care about what you want to do, what you are doing, just kind of want you to finish what they think that you need to do for in terms of experiments. Just use you as a labor I think. (Lui, F, Asia)

Specifically, Lui had an experience in an earlier lab where she felt that the PI deliberately selected longer and more labor-intensive procedures to save money because PI's knew they had students to do the work for them.

She didn't really allow students to do a lot of things because she kind of want to save money... doing biology related research you kind of spend a lot of things, a lot of money on reagents [mixtures used in chemical experiments] in experiments... One way is cheaper but takes more time and takes more labor force to do it, but the other way is a little bit more expensive, but takes less time and you don't have to spend a lot of time and effort into it. So she will always choose the cheaper one, so that's what I don't like. (Lui)

There were different rationales for the extra hours that were based on the expected norms of graduate education. Gi explained why students worked beyond their paid hours, "When you become an RA it's a little harder to distinguish your own work and the work for being an RA because it's kind of correlating. Let's just say 50 hours for total but cannot really specifically define this much hours for being an RA and this much hours is for just working beside RA" 
(Gi, M, Asia). Suzy suggested that international students work so much because it is a mutual benefit: "It's kind of like I'm not getting paid for doing the work it's kind of like my education is being paid, I will do this for free and besides that I'm being paid so that I can pay my expenses. I don't see like I'm getting paid for the work that I'm doing it's kind of like extra." (Suzy, F, Caribbean).

Overall despite being students, these participants did not refer to themselves as such. Instead their roles in academia were linked to their research work to determine new research topics, conduct experiments and perform all work tasks assigned to them by their PIs.

\section{Financially and Legally Dependent on Advisor}

Despite the aforementioned challenges of long work hours and perceptions of exploitation, the students, for the most part, did not challenge their conditions or advisors' expectations. Although some students were in the US on scholarships from their home country governments, a large number of students indicated that they were reliant on grant funding, which was directly tied to their advisor. Abrahan stated: "Yeah. So he's paying for my tuition, my health expenses, and blah, blah, blah. Everything.". This reliance created a dependent relationship whereby the advisor held the power and the student was cognizant of this power dynamic. Some students narrated how important it was to maintain a good relationship with your advisor as this has implications for one's legal status in the US.

So sometimes if your PI knows that you are contacting others they kind of get pissed off and let you go, something. It, it's just my worries, you know? It's possible and also for international student you have visa problems. If your PI stopped your visa, he terminates your I-20, you are not, you are not legally staying here. It's a big problem. One visiting scholar I know, the PI he knows he gonna change to another lab. [The supervisor] gets pissed off so he terminated the legal document immediately. So for that week he is illegal to stay here and fortunately he finds his new lab very quickly the new lab PI offered him the new legal document, but for that work he was worried so much. He worried if the immigrant office will find him and say, 'Oh you are not legal and please go back.' (Mei, F, Asia)

The reliance on funding from the advisor's grant funder or the department required students to be mindful of the things they said. Mateo recounted, "After 15 years I had the chance to be in a conference where my future adviser from Alaska was there and he said, 'Keep talking in the right voice. We have the money for supporting graduate students.' I understood that, after so many years I knew the lingo. I said, 'This is the way.' I applied and everything came in the right way" (Mateo, M, South America). Fuhua described an encounter in which he unknowingly offended his department head and was later warned to be more careful:

For the past year, when I look back, I often [thought] my advisor, [was the] person who pays me, [not the] Department Head. When I look back, I didn't notice that when I said certain things ... in a group I said something in front of them got them really...their head turned red in an instant...it's interesting that person who pays me, at first figured out several times but never directly talks to me but he talked to my advisor and my advisor talks to me to please just be aware you were saying. (Fuhua, M, Asia)

Students described feeling like a possession that was exclusively to benefit their advisor. Eshan reported that he felt that his advisor was blocking the student's path to graduation as this 
would mean that the advisor would lose the help Eshan had been providing towards the faculty member's research. Eshan was in his fifth year and had only recently taken the required comprehensive exams to progress towards completion. He lamented that other students took this exam in their third year and requests to their advisor to let him take this exam earlier had been denied.

Basically after my third year I told him, I started talking to him about my graduation stuff and he said that in biochemistry students have to do at least five years of research. So now it's even five years and he didn't basically let me do my comprehensive exam until last month... But everyone does his or her comprehensive exam in the third year. He did that because he was afraid that I may leave. (Eshan, M, Asia)

In this case, Eshan felt he had no choice but to comply and delay his progress or risk not ever completing his studies. Dayani similarly felt their goals were being ignored. She shared, "I felt like this new project that he wants to work on, he's pushing me into it so that he can say that he got some funding out of it and this is something that I have no interest in it and if I ever do it, it's because I'm his student not because of anything else. (Dayani, F, Asia). Other students were merely assigned research projects that previous students had started: “... what I'm doing now is following the prior student's so [my advisor] wants to continue that" (Sara). It appeared that some advisors were able to use student initiated research ideas as a way to continue to obtain grants to sustain their labs. Despite some of the negative experiences, many students resolved to accept the status quo focusing instead on the end goal of graduating, finding a job, and or returning to their home countries.

\section{DISCUSSION AND CONCLUSIONS}

This study critically examined the self-reported experiences of international graduate students in light of the acquisitions and mergers framework (Deschamps \& Lee, 2015). When asked about their advisors, many students reported positive experiences with their advisors in their pursuit of graduate qualifications. However, the roles that students took on in laboratories and other research settings were diverse, ranging from co-contributors to knowledge and respected collaborators to employed cheap labor that their advisors depended upon for their own gains. The concept of mergers can be seen in the way students viewed the development of their research knowledge and skills. Students felt they were learning while contributing, and that their professional goals were being met through such experiences. Conversely, the concept of acquisitions was seen in the way students felt like they were treated as mere employees doing work that was unrelated to their professional goals. In some cases, these students feared that their funding would be cut off or that they would be dismissed from the program (and consequently deported from the US) if they challenged their advisors. Whether such apprehensions were valid is unknown as this study focused only on the perceptions of the students. However, the findings do lead to important future directions for research and practice.

One area for future research is to consider examining faculty perceptions of international students. Previous research by Cantwell and Lee (2010) found that faculty may possess negative stereotypes of Asian international postdocs, preferring instead to work with domestic postdocs, but the extent to which such sentiments might also apply to international graduate students is not known. For example, the negative sentiments may be a result of cultural misunderstandings that arise from how these students were socialized in their home countries 
and their expectations of their advisors. Another area for further investigation is a comparison between the experiences of domestic graduate students and their international counterparts.

International graduate students have become a significant part of the US research enterprise and nurturing such students to be independent researchers rather than treating them as cheap labor is central to the educational mission of universities. Many of the interviewees who feared repercussions from their advisors were not aware of campus resources to report their grievances. Many suffered in silence. Thus, students should not only should be made aware of the resources, but also about their rights and actions that they can take without fear of dismissal for speaking out. It is quite likely that international students will comprise an increasing portion of graduate students in the US, especially in STEM fields. Thus, universities must not only be aware of their increasing presence, but also their experiences and explore ways to maximize the benefits both parties can offer to each other.

\section{REFERENCES}

Adrian-Taylor, S. R., Noels, K. A., \& Tischler, K. (2007). Conflict between international graduate students and faculty supervisors: Toward effective conflict prevention and management strategies. Journal of Studies in International Education, 11, 90-117. doi.org/10.1177/1028315306286313

Altbach, P. G., \& Knight, J. (2007). The internationalization of higher education: Motivations and realities. Journal of studies in international education, 11, 290-305. doi:10.1177/1028315307303542

Cantwell, B. (2011). Transnational mobility and international academic employment: Gatekeeping in an academic competition arena. Minerva, 49, 425-445. doi.org/10.1007/s11024-011-9181-3

Cantwell, B., \& Lee, J. J. (2010). Unseen workers in the academic factory: Perceptions of neo-racism among international postdocs in the United States and the United Kingdom. Harvard Educational Review, 80, 490-517. doi.org/10.17763/haer.80.4.w54750105q78p451

Cantwell, B., \& Maldonado-Maldonado, A. (2009). Four stories: Confronting contemporary ideas about globalisation and internationalisation in higher education. Globalisation, Societies and Education, 7, 289-306. doi.org/10.1080/14767720903166103.

Chapdelaine, R. F., \& Alexitch, L. R. (2004). Social skills difficulty: Model of culture shock for international graduate students. Journal of College Student Development, 45, 167-184. doi:10.1353/csd.2004.0021

Cheng, R., \& Erben, A. (2012). Language anxiety: Experiences of Chinese graduate students at US higher institutions. Journal of Studies in International Education, doi:102831531142184.

Corbin, J. M., \& Strauss, A. (1990). Grounded theory research: Procedures, canons, and evaluative criteria. Qualitative Sociology, 13(1), 3-21.

Corley, E. A., \& Sabharwal, M. (2007). Foreign-born academic scientists and engineers: Producing more and getting less than their US-born peers? Research in Higher Education, 48, 909-940. doi.org/10.1007/s11162-007-9055-6.

Deschamps, E., \& Lee, J. J. (2015). Internationalization as mergers and acquisitions: Senior international officers' entrepreneurial strategies and activities in public universities. Journal of Studies in International Education, 19: 122-139. doi.org/10.1177/1028315314538284.

Hudzik, J. K. (2014). Comprehensive internationalization: Institutional pathways to success. New York, MY: Routledge.

Kim, H. Y. (2011). International graduate students' difficulties: Graduate classes as a community of practices. Teaching in Higher Education, 16, 281-292. doi: 10.1080/13562517.2010.524922.

Knight, J. (2003). Updated internationalization definition. International Higher Education, 33, 2-3.

Kuo, Y-H. (2011). Language challenges faced by international graduate students in the United States. Journal of International Students, 1, $38-42$. 
Marginson, S. (2014). Student self-formation in international education. Journal of Studies in International Education, 18, 6-22. doi: 10.1177/1028315313513036.

Marginson, S. (2007). Global position and position taking: The case of Australia. Journal of Studies in International Education, 11, 5-32. doi: 10.1177/1028315306287530.

Marginson, S. and M. van der Wende (2007), Globalisation and Higher Education, OECD Education Working Papers, No. 8, OECD Publishing. http://dx.doi.org/10.1787/173831738240

Merriam, S. B. (2009). Qualitative research. A guide to design and implementation. San Francisco, CA: Jossy-Bass.

National Science Board. (2014). Science and engineering indicators 2014. Arlington, VA: National Science Foundation.

Pusser, B., \& Marginson, S. (201). University rankings in critical perspective. The Journal of Higher Education 84, 544-568. doi: 10.1080/00221546.2013.11777301.

Poyrazli, S., Arbona, C., Nora, A., McPherson, R., \& Pisecco, S. (2002). Relation between assertiveness, academic self-efficacy, and psychosocial adjustment among international graduate students. Journal of College Student Development, 43, 632-642.

Stephan, P. E. (2012). How economics shapes science. Cambridge, MA: Harvard University Press.

Taylor, B. J., \& Cantwell, B. (2015). Global competition, US research universities, and international doctoral education: Growth and consolidation of an organizational field. Research in Higher Education, 56, 411-441. doi:10.1007/s11162-014-9355-6

Trice, A. (2004). Mixing it up: International graduate students' social interactions with American students. Journal of College Student Development, 45, 671-687.

Webber, K. L. (2012). Research productivity of foreign-and US-born faculty: differences by time on task. Higher Education, 64, 709-729. 10.1007/s10734-012-9523-6

Zhou, Y, \& Todman, J. (2009). Patterns of adaptation of Chinese postgraduate students in the United Kingdom. Journal of Studies in International Education, 13, 467-486.

BRENDAN CANTWELL, PhD, is an Associate Professor in the Department of Educational Administration, Michigan State University, USA. Email: brendanc@msu.edu.

JENNY J LEE, PhD (corresponding author), is Professor in the Center for the Study of Higher Education, University of Arizona, USA. Email: jennylee@email.arizona.edu.

YEUKAI A MLAMBO, PhD, is a Postdoctoral Fellow in the Center for Advanced Studies in Global Education, Arizona State University, USA. Email: Yeukai.Mlambo@asu.edu. 